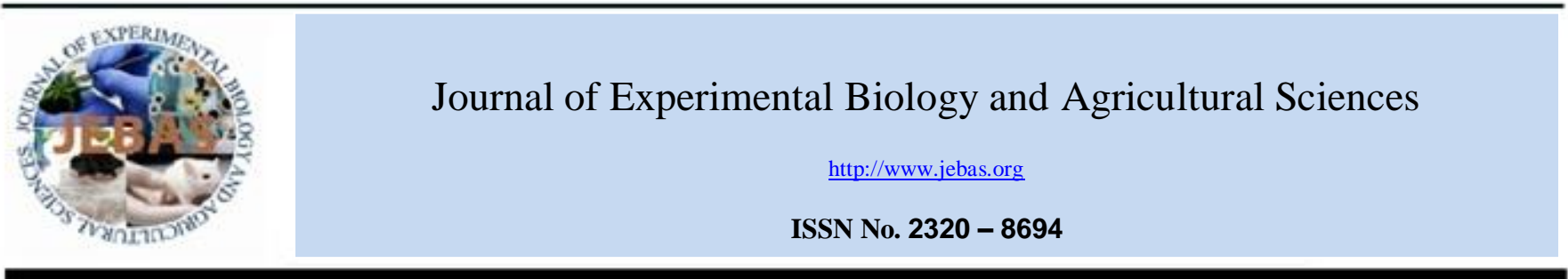

\title{
ASTHENOZOOSPERMIC BUFFALO (Bubalus bubalis) SPERM TAIL IS ASSOCIATED WITH LOWER EXPRESSION OF TEKTIN-2 AND SPAG6 AND HIGHER EXPRESSION OF SPECIFIC TYROSINE PHOSPHORYLATED PROTEINS
}

\author{
B. C. Divyashree ${ }^{1,2}$, Sudhir C. Roy ${ }^{1, *}$, Vijayasaraswathy S. Gurupriya ${ }^{1}$ \\ ${ }^{1}$ Molecular Biology Laboratory, Indian Council of Agricultural Research-National Institute of Animal Nutrition and Physiology, Hosur Road, Adugodi, Bangalore-560030, India
${ }^{2} \mathrm{PhD}$ Scholar, Department of Biochemistry, Centre for Post Graduate Studies, Jain University, Jayanagar 3rd Block, Bangalore-560011, India
}

Received - December 27, 2018; Revision - January 03, 2019; Accepted - January 16, 2019

Available Online - February 5, 2019

DOI: http://dx.doi.org/10.18006/2019.7(1).86.94

KEYWORDS
Asthenozoospermia
Buffalo
Motility
SPAG6
Sperm
Tektin-2
Tyrosine phosphorylated
proteins

\begin{abstract}
Study of motility-associated proteins is a direct approach to decode the underlying mechanisms of the motility-regulation pathway in a mammalian spermatozoon. In this aspect, attempts were made to characterize and study the expression pattern of two candidate motility-associated proteins of mammalian sperm such as Tektin-2 and SPAG6 and post-translationally modified tyrosine phosphorylated proteins between the two defined groups of buffaloes: normozoospermic (NS) and asthenozoospermic (AS). 1-D Western blot demonstrated three Tektin-2 immunoreactive bands (95.3, 55.7 and $33.0 \mathrm{kDa}$ ) in buffalo sperm tails. Of these, the intensity of $95.3 \mathrm{kDa}$ band reduced significantly $(\mathrm{P} \leq 0.05)$ in sperm tail of AS group as compared to that of NS group. Similarly, the sperm tail demonstrated a single SPAG6-immnunoreactive band of $31.6 \mathrm{kDa}$ that reduced significantly $(\mathrm{P} \leq 0.05)$ in sperm tail of AS group as compared to that of NS group. Both AS and NS group sperm tail demonstrated at least five tyrosine phosphorylated proteins $(89.5,53.3,44.5,30.9$ and $16.7 \mathrm{kDa})$. Of these, the intensity of $44.5 \mathrm{kDa}$ band was significantly higher $(\mathrm{P} \leq 0.05)$ in AS group as compared to that of NS group. Interestingly, within the AS group, degree of expression of $53.3 \mathrm{kDa}$ tyrosine phosphorylated protein was bull-specific. The findings of the present study have demonstrated that AS group of buffalo bulls are associated with lower expression of Tektin-2 and SPAG6 and higher expression of specific tyrosine phosphorylated proteins.
\end{abstract}

* Corresponding author

E-mail: scroy67@gmail.com; scroy67@yahoo.co.in (Sudhir C. Roy)

Peer review under responsibility of Journal of Experimental Biology and Agricultural Sciences.

Production and Hosting by Horizon Publisher India [HPI] (http://www.horizonpublisherindia.in/).

All rights reserved.
All the article published by Journal of Experimental Biology and Agricultural Sciences is licensed under a Creative Commons Attribution-NonCommercial 4.0 International License Based on a work at www.jebas.org.

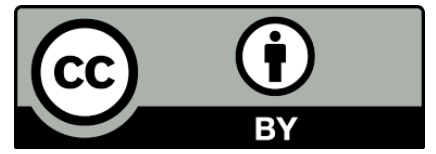




\section{Introduction}

Fertilization in mammals is achieved by the fusion of a motile sperm and a reproductively mature egg through a highly orchestrated but less understood process. In cattle, about half of the fertilization failure is attributed to defective bull (Park et al., 2012). Moreover in a herd, a substantial number of buffalo bulls suffer from low sperm motility called asthenozoospermia (Guruprasad et al., 2011). However, the precise reason and mechanism for this reduced motility of buffalo sperm are not known. Mammalian spermatozoon, being a terminally differentiated cell can neither undergo transcription nor translation (Toshimori \& Eddy, 2015). The principal mechanism by which a mammalian spermatozoon acquires motility is primarily through the post-translational modifications (PTM) of its proteins and metabolic activities (Naresh \& Atreja, 2015). Phosphorylation of sperm proteins at tyrosine residues is one of the significant PTM. In human sperm, the tyrosine phosphorylation of most proteins was concentrated to the sperm tail (Ficarro et al., 2003). The flagellar/tail proteins involved in the motility regulation pathway are tyrosine phosphorylated either through cAMP/PKA pathway or calcium signalling pathway (Turner, 2006). Thus, it is of prime interest to study such flagellar/tail proteins of buffalo sperm that are involved in sperm motility regulation and the proteins that are phosphorylated at tyrosine residues.

Tektins are a group of $\alpha$-helical structural proteins involved in the construction of sperm cilia and flagella and possess a nonapeptide consensus sequence RPNVELCRD conserved right from the sea urchins to humans, suggesting its significant role in sperm functions (Amos, 2008). Basically, three major tektin polypeptides of molecular masses 47, 51 and $55 \mathrm{kDa}$ were originally isolated from sea urchin (Strongylocentrotus purpuratus) sperm flagellar outer doublet microtubules (Linck \& Stephens, 1987). Tektins that have been identified in mammals include Tektin 1-5. Tektin-1, a $50 \mathrm{kDa}$ protein, was found to be expressed in mouse spermatocytes and spermatids and localized to the centrosomes of round spermatid and caudal end of maturing spermatozoa (Larrson et al., 2000). Tektin-2 was found to be crucial for integrity of the dynein inner arm and Tektin-2 null mice are infertile due to loss of sperm motility (Tanaka et al., 2004). Tektin-3 deficient male mice demonstrated reduced progressive sperm motility; however other aspects like sperm count and reproductive status remain undisturbed (Roy et al., 2009). Tektin- 4 is essential for the organized beating of sperm flagellum and tektin-4 null mice tend to lose progressive motility (Roy et al., 2007). Tektin-5 was found to be closely associated with the inner side of mitochondrial sheath as revealed by immunogold electron microscopy. Tektin-5 was localised specifically to the middle piece of rat sperm flagellum (Murayama et al., 2008). Thus, Tektins play a crucial role in maintenance of sperm motility and fertility. Men with oligoasthenozoospermia demonstrated reduced expression of Tektin-2 than those with normozoospermia (Bhilawadikar et al., 2013).

Sperm associated antigens (SPAGs) are a group of sperm proteins that elicit auto-antibodies and cause infertility in males (Inaba, 2011). Among the identified SPAGs, SPAG6, 8-9, and 11 are associated with male fertility. SPAG6 knockout mice demonstrate impaired sperm motility and male infertility (Sapiro et al., 2002). SPAG6 deficient mice either survive but demonstrate male sterility or die due to hydrocephalus (Teves et al., 2014). A study reported that, SPAG6 is essential for the normal formation and function of immunological synapse, thus demonstrating the significance of SPAG6 to fertility (Cooley et al, 2016). SPAG8 plays an important role in CREM-ACT (cAMP response element modulator- activator) mediated gene transcription during spermatogenesis (Wu et al., 2010). SPAG9 is a sperm surface protein and have been found to play role in sperm-egg interaction (Jagadish et al., 2005); SPAG11 isoforms were abundant in the rat male reproductive tract and implicated to play a role in immunity (Yenugu et al., 2006).

Protein tyrosine phosphorylation is one of the most significant intracellular signalling events associated with sperm motility and capacitation in several species (Visconti et al., 1995; GalantinoHomer et al., 1997; Roy \& Atreja, 2008). A 55 kDa sperm protein, identified as glycogen synthase kinase-3 $\alpha$, was found to be tyrosine phosphorylated during epididymal maturation of bovine sperm (Vijayaraghavan et al., 1997; Vijayaraghavan et al., 2000). Tyrosine phosphorylation of two sperm proteins viz. nuclear protein localization protein 4 homologue $(68 \mathrm{kDa})$ and keratin, type-II cytoskeletal $1 \quad(66 \mathrm{kDa})$ were increased significantly in AS human sperm (Chan et al., 2009). Tyrosine phosphorylation of glucose regulated protein 78 (GRP78) was found to be reduced significantly in sperm of AS human semen (Parte et al., 2012). A $56 \mathrm{kDa}$ protein was found to be tyrosine phosphorylated in cryopreserved bovine sperm that are associated with premature capacitation (Cormier \& Bailey, 2003).

To the best of our knowledge, the specific association of various isoforms of Tektin-2, SPAG6 and protein tyrosine phosphorylation to sperm motility has not been explored so far in any ruminant species including buffaloes. Thus, it was hypothesized that the expression pattern of Tektin-2, SPAG6 and protein tyrosine phosphorylation vary between normozoospermic (NS) and asthenozoospermic (AS) groups of buffalo semen.

\section{Materials and Methods}

Semen samples were collected twice a week from seven Murrah buffalo (Bubalus bubalis) bulls, between 3-5 years of age, maintained under isomanagerial conditions at Nandini Sperm 
Station (NSS), Hessarghatta, Bangalore, Karnataka, India. Animal management and semen collection protocols of the sperm station were as per the relevant guidelines and regulations of the state government.

\subsection{Collection of buffalo semen and analysis of sperm motility}

Semen ejaculates from Murrah buffalo bulls were collected using an artificial vagina (IMV, France) maintained at $40^{\circ} \mathrm{C}$. Shortly after collection, semen samples were assessed for their mass activities by light microscopy at $10 \mathrm{X}$ magnifications. A minor aliquot of semen sample was diluted (1:10) in spermTyrode's albumin lactate pyruvate hepes buffer (sp-TALPH) media, pH 7.4 [100-mM NaCl, 3.1-mM KCl, 0.4-mM EDTA di-sodium salt, $0.4-\mathrm{mM} \quad \mathrm{MgCl}_{2} \cdot 6 \mathrm{H}_{2} \mathrm{O}, \quad 0.3-\mathrm{mM}$ $\mathrm{NaH}_{2} \mathrm{PO}_{4} \cdot 2 \mathrm{H}_{2} \mathrm{O}, 21.6$-mM Sodium lactate, 2-mM CaCl $2 \cdot 2 \mathrm{H}_{2} \mathrm{O}$, 1-mM Sodium pyruvate, $40-\mathrm{mM}$ hepes, $10-\mathrm{mM} \mathrm{NaHCO}_{3}$ and $1 \mathrm{mg} / \mathrm{mL}$ (w/v) polyvinyl alcohol (PVA, 30-70 kDa)] and the progressive motility of sperm was evaluated by computer assisted semen analyser (CASA, version 3.2.0; Microptic, Barcelona, Spain) (Dott \& Foster, 1979). Based on the percentage of progressive motility of sperm as assessed by CASA, buffalo semen samples were categorized in to two groups viz., normozoospermic (NS, progressive motility $\geq 70 \%, \mathrm{n}=8$ ) and asthenozoospermic (AS, progressive motility $\leq 40 \%, \mathrm{n}=10$ ). Each of the samples for NS and AS groups was from different bull. Two ejaculates of the same bull collected at 30 minutes interval were pooled and this constituted one semen sample. Semen samples having progressive motility above $40 \%$ and below $70 \%$ were excluded for the study.

\subsection{Separation of buffalo sperm head and tail}

The major aliquot of semen was centrifuged to separate sperm pellet and seminal plasma as described earlier (Divyashree \& Roy, 2018). The sperm pellet obtained was subjected to sonication followed by sucrose gradient centrifugation to separate sperm head and tail according to the method of O'Brien \& Bellve (1980) as modified by Carrera et al. (1994). Briefly, the sperm pellet was washed once with S-EDTA buffer, pH 6.0 [75 mM NaCl, 1\% (w/v SDS, $24 \mathrm{mM}$ EDTA, pH 6.0] and resuspended in appropriate volume of S-EDTA buffer, $\mathrm{pH}$ 6.0. The sperm suspension was then sonicated (VCX130; Sonics Vibra Cell, Sonics \& Materials Inc., Newtown, U.S $)$ at $40 \%$ amplitude for 8 cycles at $4{ }^{\circ} \mathrm{C}(15 \mathrm{sec}$ pulse ON, $10 \mathrm{sec}$ pulse OFF). The suspension was then vortexed (Spinix, Tarsons, Kolkata, India) for 1 minute each and stored at $4^{\circ} \mathrm{C}$ for 1 hour with intermittent vortexing at 10 minutes interval. The suspension was then observed for separation of head and tail under phase contrast microscopy (Eclipse-80i, Nikon Instruments Incorporation, Tokyo, Japan). The suspension was then layered on $5 \mathrm{X}$ volumes of $1.6 \mathrm{M}$ sucrose in S-EDTA and the tubes were centrifuged at $5000 \mathrm{X} \mathrm{g}$ for 1 hour at $20^{\circ} \mathrm{C}$. The SDS-resistant tail structures were separated as an interface in the sucrose gradient which was collected and stored at $-20^{\circ} \mathrm{C}$ for further use.

\subsection{SDS-PAGE and Western blot for detection of Tektin-2, SPAG6 and tyrosine phosphorylated proteins}

Sperm tail suspension was added with equal volumes of $2 \mathrm{x}$ reducing sample of Laemmli (1970) with $100 \mathrm{mM}$ DTT as the reducing agent. The solubilised proteins were resolved by $10 \%$ uniform reducing SDS-PAGE according to the method of Laemmli (1970). The molecular masses of separated proteins were determined by applying standard protein molecular weight markers (Precision Plus dual colour standards, Bio-Rad, Hercules, California, US) in a reference well.

Proteins separated by SDS-PAGE gels were transferred on to the Immobilon-P PVDF membrane (pore size, $0.45 \mathrm{~mm}$ ) as described earlier (Divyashree \& Roy, 2018). The blots were incubated with goat anti-human Tektin-2 and SPAG6 polyclonal antibodies @ $2.6 \mu \mathrm{g} / \mathrm{mL}$ and $2.0 \mu \mathrm{g} / \mathrm{mL}$, respectively (sc-160104, sc-165528; Santa Cruz Biotech, Dallas, Texas, US); mouse monoclonal antiphosphotyrosine antibody @ $1.0 \mu \mathrm{g} / \mathrm{mL}$ (P1869, Sigma-Aldrich, St. Louis, MO, USA) for 2 hours at room temperature. The amino acid sequence homologies between human and predicted buffalo Tektin-2 and SPAG6 are $91 \%$ and $96 \%$ respectively (https://blast.ncbi.nlm.nih.gov/Blast). After washing with TBS-T, the membranes were incubated in secondary antibodies; rabbit anti-goat immunoglobulin conjugated with horseradish peroxidase (dilution $1: 1,60,000$ and $1: 1,80,000$ for Tektin2 and SPAG6 respectively; A5420, Sigma-Aldrich, St. Louis, MO, USA) and anti-mouse immunoglobulin conjugated with horseradish peroxidase (dilution 1:50,000; A2554, Sigma-Aldrich, St. Louis, MO, USA) for 1 hour at room temperature and washed again with TBS-T. Subsequently, the membrane was treated with Clarity Western ECL substrate (Bio-Rad Laboratories Inc, Hercules, CA, USA) to visualize the peroxidase activities, as per manufacturer's instructions. The enhanced chemiluminescence signal that developed on the membrane was captured on X-ray films (Fujifilm Corporation, Tokyo, Japan) in a dark room. The exposed films were processed and developed.

\subsection{X-ray film imaging and densitometry of detected proteins}

Following chemiluminescence detection of the proteins, the X-ray films were photographed by a gel documentation system (LAS3000; Fujifilm, Tokyo, Japan). The molecular mass and densitometric analyses of the detected protein bands were performed using the Multi Gauge analysis software (version 2.2, Fujifilm, Tokyo, Japan). The band having lowest intensity was assigned a base value of 100 to determine the relative intensities of other bands with respect to the reference band. Beta-actin and alpha-tubulins are not good loading controls for immunoblotting 
for various reasons (Dittmer \& Dittmer, 2006; Thacker et al., 2016; Moritz, 2017). Hence, Ponceau S staining (Salinovich \& Montelaro, 1986) method was used as a loading control for the western blot.

\subsection{Statistical analysis}

Data obtained were initially tested by Shapiro-Wilk test for their normal distribution. Then the data were analyzed by independent t-test to determine whether there is a statistically significant difference between the means of two groups (NS vs. AS). Both the analyses were performed using SPSS software, version 18.0 (SPSS Inc., Chicago, IL). Data are presented as mean \pm SEM. A difference with value $\mathrm{P}<0.05$ was considered statistically significant.

\section{Results}

The progressive motility percentage of semen samples of NS and AS group of Murrah buffalo were 82.0 $\pm 5.05 \quad(77.1-92.7, \mathrm{n}=4)$ and $32.3 \pm 3.90(24.8-37.8, n=3)$, respectively. Following sucrose gradient centrifugation of buffalo whole sperm pellet in S-EDTA buffer, SDSresistant tail structures appeared in the interface, whereas sperm heads settled as pellet. SDS-resistant tails were observed under a phase contrast microscope (Eclipse-80i, Nikon Instruments Incorporation, Tokyo, Japan) as longitudinal tubular structures (Figure 1).
The 1-D western blot analysis of Tektin-2 demonstrated at least three immunoreactive protein bands such as 95.3, 55.7 and 33.0 $\mathrm{kDa}$ in both NS and AS buffalo sperm tail fraction with different bulls (Figure 2A). Further, densitometric analyses revealed that the intensity of $95.3 \mathrm{kDa}$ Tektin-2 immunoreactive band of AS group sperm tail was significantly lower $(\mathrm{P}<0.05)$ than that of the NS group (Figure 2B). Contrastingly, the intensity of 55.7 and $33.0 \mathrm{kDa}$ band of AS buffalo sperm tail fraction did not vary significantly with that of NS sperm tail fraction.

Western blot detection of SPAG6 revealed a single immunoreactive band of $31.6 \mathrm{kDa}$ in NS and AS group of sperm tail fraction (Figure 3A) and densitometric analysis of the same band showed a significantly lower expression in AS sperm tail fraction as compared to that of NS group (Figure 3B)

Western blot analysis to detect tyrosine phosphorylated proteins in buffalo sperm tail fraction portrayed at least five immunoreactive bands viz., 89.5, 53.3, 44.5, 30.9 and $16.7 \mathrm{kDa}$ (Figure 4A). Tyrosine phosphorylation of a $44.5 \mathrm{kDa}$ sperm tail protein was significantly higher in AS group when compared with that of NS group (Figure 4B). Interestingly, in one bull of AS group, the tyrosine phosphorylation of a $53.3 \mathrm{kDa}$ protein was significantly higher as compared to that of other bulls of the same group as well as all the bulls of the NS group.

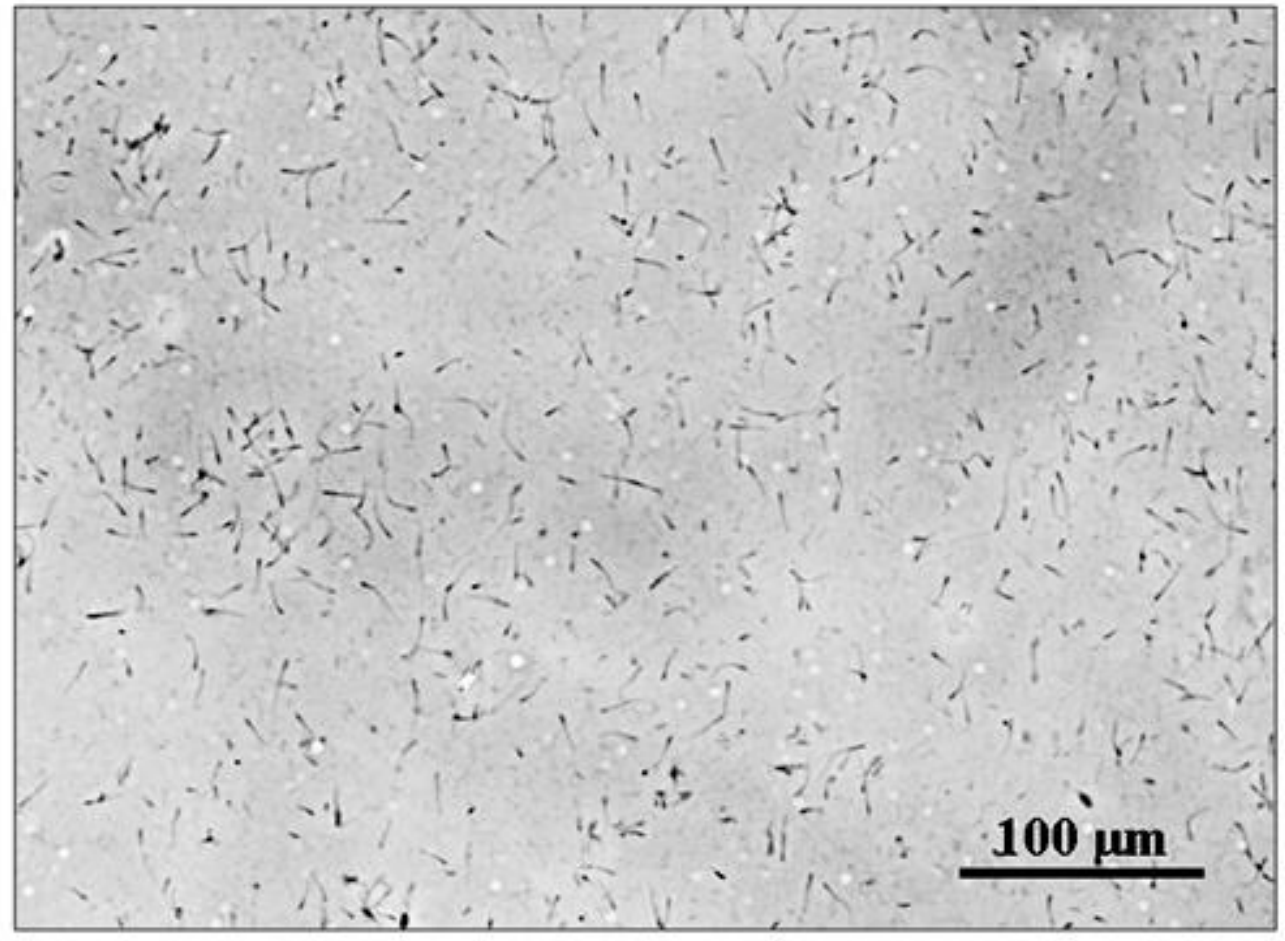

Figure 1 Photomicrograph demonstrating sperm tails separated from buffalo spermatozoa following sucrose gradient centrifugation under phase contrast optics. Scale bar $=100 \mu \mathrm{m}$. 

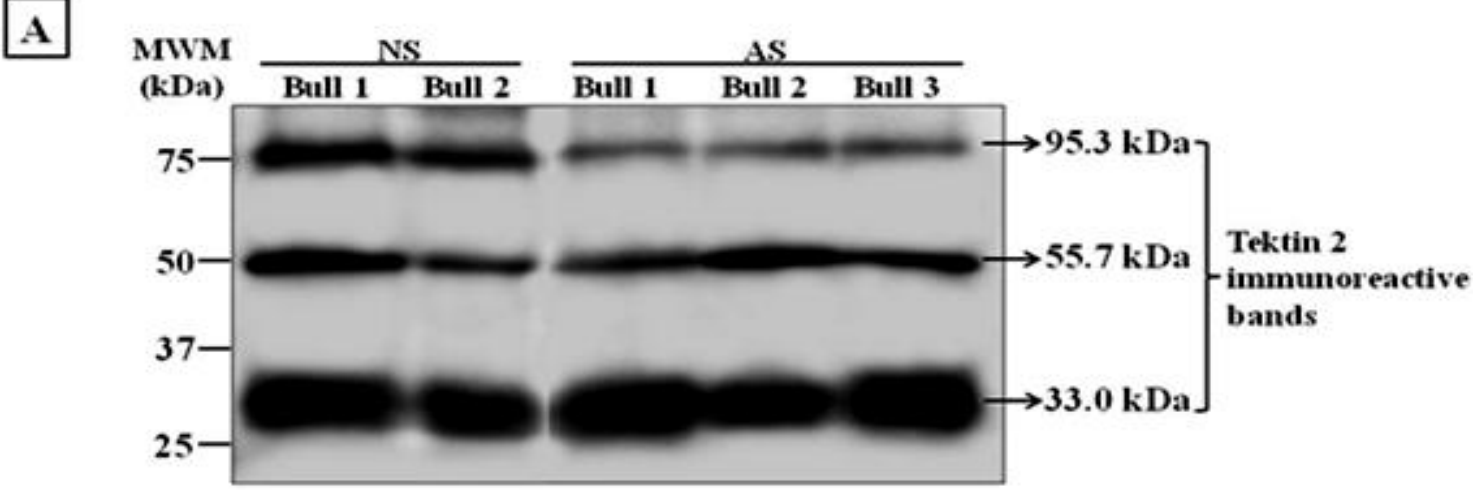

B

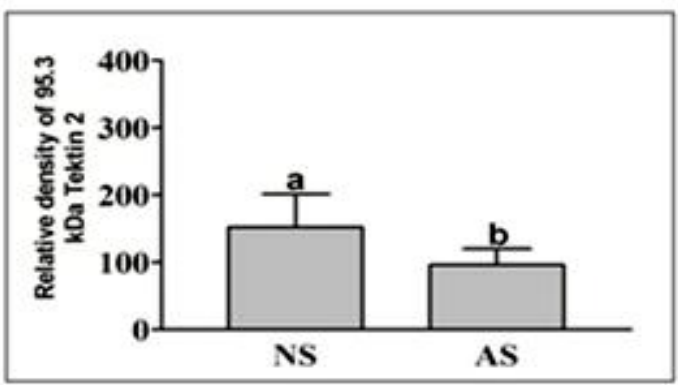

Figure 2A A representative Western blot for detection of Tektin-2 protein in buffalo sperm tail fractions. Sperm tail proteins were separated using uniform 10\% SDS-PAGE. Tektin-2 protein was detected using goat anti-human Tektin-2 polyclonal antibody. Approximately, $30 \mu \mathrm{g}$ of proteins were loaded in each well. MWM: molecular weight markers; NS: normozoospermic sperm tail proteins; AS: asthenozoospermic sperm tail proteins; 2B. Densitometric analysis of $95.3 \mathrm{kDa}(\mathrm{NS}, \mathrm{n}=2$; AS, n=3) Tektin-2 protein band as shown in Fig.2A. The data are expressed as the mean \pm standard error of the mean. Different letters above bars indicate significant differences $(\mathrm{P}<0.05)$ between different groups.

\section{A}

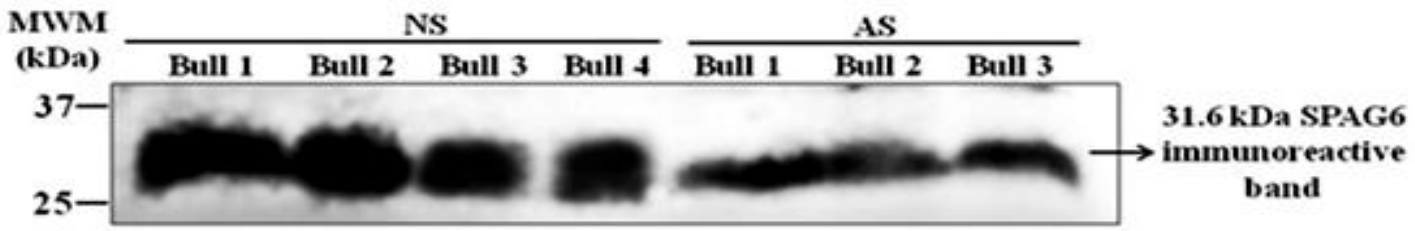

B

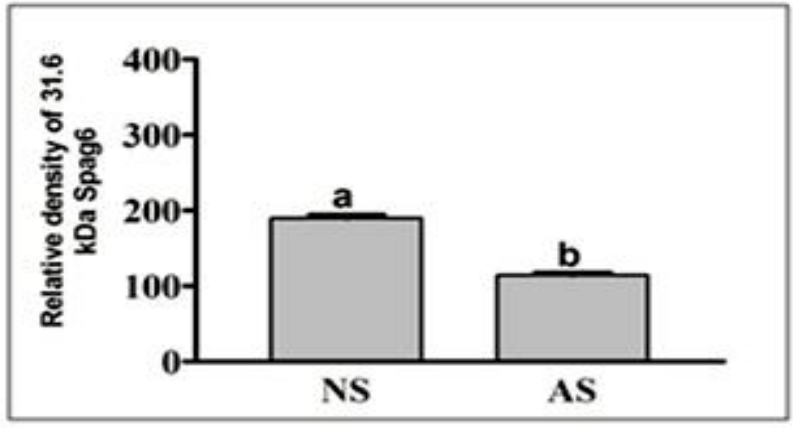

Figure 3A A representative Western blot for detection of SPAG6 protein in buffalo sperm tail fractions. Sperm tail proteins were separated using uniform 10\% SDS-PAGE. SPAG6 protein was detected using goat anti-human SPAG6 polyclonal antibody. Approximately, $30 \mu \mathrm{g}$ of proteins were loaded in each well. MWM: molecular weight markers; NS: normozoospermic sperm tail proteins; AS: asthenozoospermic sperm tail proteins. 3B. Densitometric analysis of $31.6 \mathrm{kDa}(\mathrm{NS}, \mathrm{n}=4$; AS, n=3) SPAG6 protein band of Fig.3A. The data are expressed as the mean \pm standard error of the mean. Different letters above bars indicate significant differences $(\mathrm{P}<0.05)$ between different groups. 


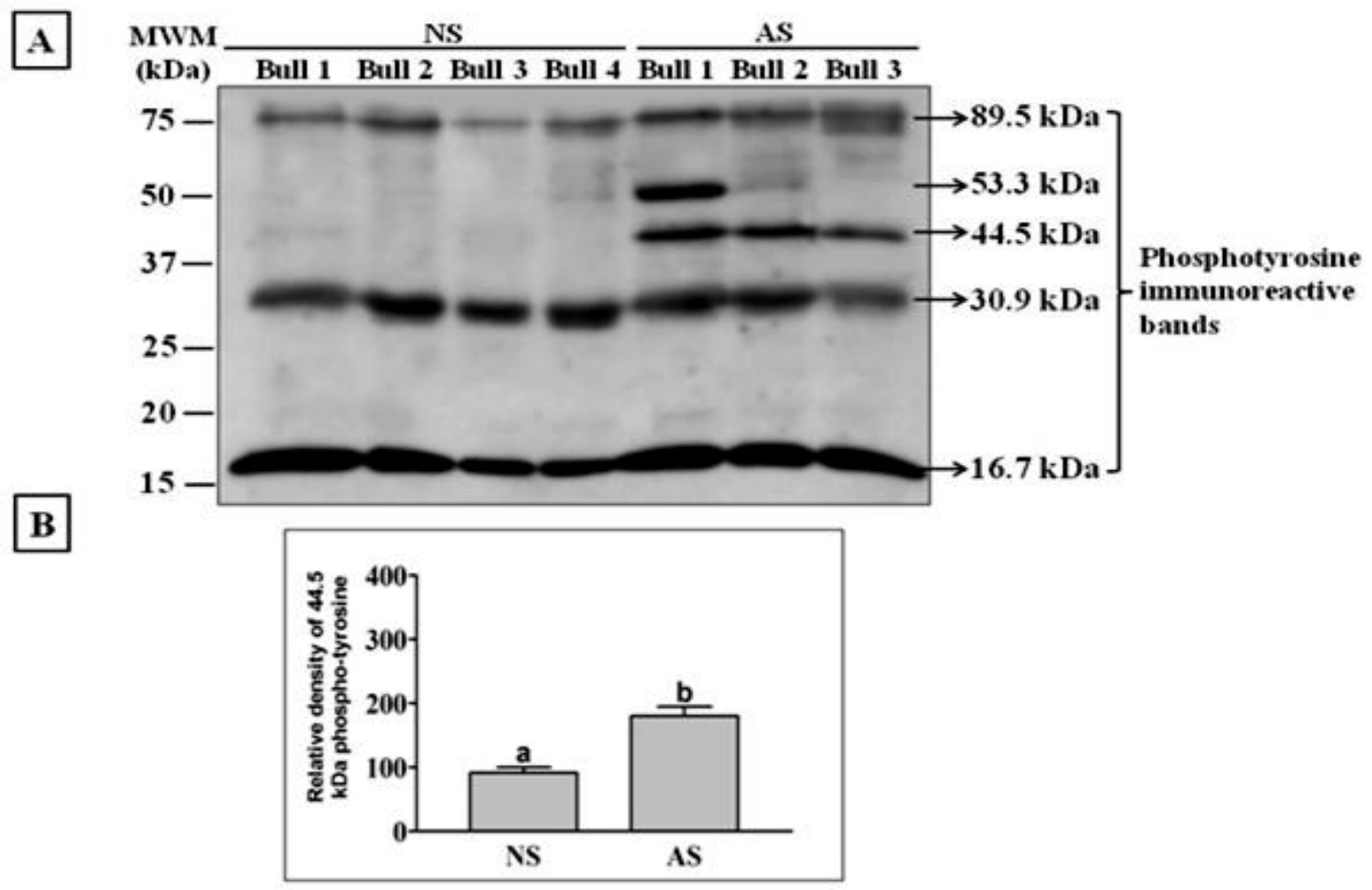

Figure 4A A representative Western blot for detection of tyrosine phosphorylated proteins in buffalo sperm tail fractions. Sperm tail proteins were separated using uniform 10\% SDS-PAGE. Phosphotyrosine protein was detected using mouse monoclonal anti-phosphotyrosine antibody. Approximately, $20 \mu \mathrm{g}$ of proteins were loaded in each well. MWM: molecular weight markers; NS: normozoospermic sperm tail proteins; AS: asthenozoospermic sperm tail proteins; 4B. Densitometric analysis of $44.5 \mathrm{kDa}$ tyrosine phosphorylated protein band of Figure 4A (NS, n=4; AS, $n=3)$. The data are expressed as the mean \pm standard error of the mean. Different letters above bars indicate significant differences $(P<0.05)$ between different groups.

\section{Discussion and conclusions}

The present study evidenced differential expression of Tektin-2, SPAG6 and tyrosine phosphorylated proteins in two different groups of buffalo sperm tails. The AS group of buffalo semen was associated with significantly lower expression of Tektin-2 and SPAG6 and higher expression of two specific tyrosine phosphorylated proteins (44.5 and $53.3 \mathrm{kDa})$.

In the present study, both groups of buffalo bull sperm demonstrated three immunoreactive Tektin-2 isoforms (95.3, 55.7, and $33 \mathrm{kDa}$ ). Earlier, the molecular mass of Tektin-2, so far reported in Homo sapiens, was 46 and $56 \mathrm{kDa}$ (Iguchi et al., 2002). This variation in the isoforms may be attributed to species difference or cross reactivity of the heterologous anti-human Tektin-2 polyclonal antibody used in the study. Among the three immunoreactive isoforms of Tektin-2 detected by 1-D Western blot, only the $95.3 \mathrm{kDa}$ band demonstrated a significantly lower expression in AS group sperm tails as compared to that of NS sperm tails. The antibody might have also cross-reacted with intermediate filament networks/ intermediate filament proteins as suggested earlier (Chang \& Piperno., 1987; Steffen \& Linck., 1989). In a recent study, a $49 \mathrm{kDa}$ Tektin-2 expression was reported to be positively correlated with sperm motility in buffalo bulls (Xiong et al., 2018). However, in present study, at least three molecular weight forms of Tektin-2 immunoreactive protein bands were detected and of these, only the $95.3 \mathrm{kDa}$ band was highly expressed in NS group bulls. Significantly lower expression of a 95.3 kDa Tektin-2 isoforms in AS group sperm tail consolidates the functional significance Tektin-2 in buffalo bulls.

In buffalo, the $31.6 \mathrm{kDa}$ SPAG6 immunoreactive band was significantly reduced in AS group buffalo sperm tails as compared to that of NS group. SPAG6 is an important structural protein of sperm tail as SPAG6 knockout mice demonstrated impaired sperm motility and male infertility (Sapiro et al., 2002). SPAG6 deficient mice either survive but demonstrate male sterility or die due to hydrocephalus (Teves et al., 2014). Impaired sperm motility of SPAG6 knock-out mice was attributed to the dysfunction of central apparatus and not due to structural abnormalities in the 
flagella (Sapiro et al., 2002). Lower expression of SPAG-6 in AS group of buffalo semen may be attributed for lower sperm motility and this specific association of SPAG6 to sperm motility in buffalo has not been reported so far.

To the best of our knowledge, this is the first report to demonstrate the higher expression of tyrosine phosphorylated proteins (53.3 and $44.5 \mathrm{kDa}$ ) in AS group buffalo sperm tail as compared to that of the NS group. Apart from higher expression of $53.3 \mathrm{kDa}$ band in AS group, there were also differences in the intensities/ expression pattern among the AS group of bulls indicating individual bull-to bull variation even within a same group. Further, the $44.5 \mathrm{kDa}$ band also displayed significantly higher expression in AS group of buffalo sperm tail as compared to that of NS group. During the course of sperm motility regulation pathway, tyrosine phosphorylation is a significant event that leads the sperm to a motile state (Tash \& Bracho, 1998). Significantly higher expression of specific tyrosine phosphorylated proteins in AS group sperm tail may be an indication of early or premature capacitation of sperm, as significantly higher percentage of acrosomes are lost from AS group spermatozoa as compared to that of NS group sperm (unpublished observation). Buffalo sperm has been reported to undergo spontaneous capacitation even in the absence of heparin (Roy \& Atreja, 2009). In an earlier study, tyrosine phosphorylation served as an indicator of sperm capacitation status in fresh and cryopreserved stallion and bovine spermatozoa (Pommer \& Meyers, 2002; Cormier \& Bailey, 2003). Capacitation, being a timedependent event can affect the stages of fertilization process, if there are any advances or delay in its initiation. Thus, characterization of these highly expressed tyrosine phosphorylated proteins in AS group of buffalo semen is of greater significance. Further, it would be interesting to identify these proteins after 2-Dimensional gel electrophoresis followed by Mass spectrometric identification so as to determine the specific functional significance of tyrosine phosphorylation in the two defined groups of buffalo bulls.

In the present study, attempts were made for the first time to determine the association of buffalo sperm motility with the expression pattern of two structural proteins i.e. Tektin-2 and SPAG6 and specific tyrosine phosphorylated proteins. Higher expression of specific tyrosine phosphorylated proteins in sperm tail of AS group semen may be an indicator of premature capacitation of sperm. Sperm motility being a key requisite for fertility, molecular identification of such motility-associated proteins is a crucial step ahead to unlock the mechanism of reduced motility in AS group of buffalo sperm.

\section{Conflicts of interest}

The authors declare that there is no conflict of interest for the contents of the manuscript.

\section{Acknowledgements}

The authors express their sincere thanks to the Director, National Institute of Animal Nutrition and Physiology (NIANP), Bangalore for providing the fund and research facilities. The study was supported partly by funding from the Department of Biotechnology (DBT), Govt. of India (Grant No. BT/PR3595/AAQ/1/482/2011). The authors also thank the Director and staff, Nandini Sperm Station, Hessarghatta, Bangalore for providing the semen samples to the present study. The first author also thanks the Director, NIANP and the Pro Vice Chancellor, Jain University, Bangalore for providing an opportunity to her for enrolling into Ph.D. programme and pursue the same at NIANP.

\section{References}

Amos LA (2008) The tektin family of microtubule-stabilizing proteins. Genome Biology 9: 229.1-229.8.

Bhilawadikar, R, Zaveri K, Mukadam L, Naik S, Kamble K, Modi D, Hinduja I (2013) Levels of Tektin 2 and CatSper 2 in normozoospermic and oligoasthenozoospermic men and its association with motility, fertilization rate, embryo quality and pregnancy rate. Journal of Assisted Reproduction and Genetics $30: 513-523$

Carrera A, Gerton GL, Moss SB (1994) The major fibrous sheath polypeptide of mouse sperm: structural and functional similarities to the A-kinase anchoring proteins. Developmental Biology 165: 272-284.

Chan, C, Shui H, Wu C, Wang C, Sun G, Chen H, Wu G (2009) Motility and protein phosphorylation in healthy and asthenozoospermic sperm. Journal of Proteome Research 8: 5382-5386.

Chang X, Piperno G (1987) Cross-reactivity of antibodies specific for flagellar tektin and intermediate filament subunits. The Journal of Cell Biology 104:1563-1568.

Cooley LF, El Shikh ME, Li W, Keim RC, Zhang Z, Strauss JF, Zhang Z, sConrad DH (2016) Impaired immunological synapse in sperm associated antigen 6 (SPAG6) deficient mice. Scientific Reports 6: Article number: 25840. doi:10.1038/srep25840.

Cormier N, Bailey JL (2003) A differential mechanism is involved during heparin- and cryopreservation-induced capacitation of bovine spermatozoa. Biology of Reproduction 69:177-185.

Dittmer A, Dittmer J (2006) $\beta$-Actin is not a reliable loading control in Western blot analysis. Electrophoresis 27: 2844-2845. 
Divyashree BC, Roy SC (2018) Species specific and differential expression of BSP-5 and other BSP variants in normozoospermic and asthenozoospermic buffalo (Bubalus bubalis) and cattle (Bos taurus) bulls. Theriogenology 106:279-286.

Dott HM, Foster GCA (1979) The estimation of sperm motility in semen, on a membrane slide by measuring the area change frequency with an image analysing computer. Journal of Reproduction and Fertility 55:161-166.

Ficarro S, Certihin O, Westbrook VA, White F, Jayes F, Kalab K, Marto JA, Shabanowitz J, Herr JC, Hunt DF, Visconti PE (2003) Phosphoproteome analysis of capacitated human sperm. Evidence of tyrosine phosphorylation of a kinase-anchoring protein 3 and valosin-containing protein/ p97 during capacitation. Journal of Biological Chemistry 278: 11579-11589.

Galantino-Homer HL, Visconti PE, Kopf GS (1997) Regulation of protein tyrosine phosphorylation during bovine sperm capacitation by a cyclic adenosine 3', 5'-monophosphatedependent pathway. Biology of Reproduction 56: 707-719.

Guruprasad J, Roy J, Das D, Mukherjee A, Polley S, Chakravarty AK, Mohanty TK, De S (2011) Asthenozooospermia in a crossbred bull. Indian Veterinary Journal 88: 119-120.

Iguchi N, Tanaka H, Nakamura Y, Nozaki M, Fujiwara T, Nishimune Y (2002) Cloning and characterization of the human tektin-t gene. Molecular Human Reproduction 8: 525-530.

Inaba K (2011) Sperm flagella: comparative and phylogenetic perspectives of protein components. Molecular Human Reproduction 17: 524-538.

Jagadish N, Rana R, Selvi R, Mishra D, Garg M, Yadav S, Suri A (2005) Characterization of a novel human spermassociated antigen 9 (SPAG9) having structural homology with c-Jun N-terminal kinase-interacting protein. Biochemical Journal 389: 73-82.

Laemmli UK (1970) Cleavage of structural proteins during the assembly of the head of bacteriophage T4. Nature 227:680-685.

Larrson M, Norrander J, Graslund S, Brundell E, Linck R, Stahl S, Hoog C (2000) The spatial and temporal expression of Tekt1, a mouse tektin $\mathrm{C}$ homologue, during spermatogenesis suggest that it is involved in the development of the sperm tail basal body and axoneme. European Journal of Cell Biology 79:718-725.

Linck W, Stephens, RE (1987) Biochemical characterization of tektins from sperm flagellar doublet microtubules. The Journal of Cell Biology 104:1069-1075.
Moritz CP (2017) Tubulin or not tubulin: heading toward total protein staining as loading control in Western blots. Proteomics doi: 10.1002/pmic.201600189.

Murayama E, Yamamoto E, Kaneko T, Shibata Y, Inai T, Iida H (2008) Tektin5, a new Tektin family member, is a component of the middle piece of flagella in rat spermatozoa. Molecular Reproduction and Development 75:650-658.

Naresh S, Atreja SK (2015) The protein tyrosine phosphorylation during in vitro capacitation and cryopreservation of mammalian spermatozoa. Cryobiology 70: 211-216.

O'Brien DA, Bellve AR (1980) Protein constituents of the mouse spermatozoon; I: An electrophoretic characterization. Developmental Biology 75:386-404.

Park Y, Kwon W, Oh S, Pang M (2012) Fertility-Related Proteomic Profiling Bull Spermatozoa Separated by Percoll. Journal of Proteome Research 11: 4162-4168.

Parte PP, Rao P, Redij S, Lobo V, D'Souza SJ, Gajbhiye R, Kulkarni V (2012) Sperm phosphoproteome profiling by ultra performance liquid chromatography followed by data independent analysis (LC-MSE) reveals altered proteomic signatures in asthenozoospermia. Journal of Proteomics 75: 5861-5871.

Pommer A, Meyers S (2002) Tyrosine phosphorylation is an indicator of capacitation status in fresh and cryopreserved stallion spermatozoa. Theriogenology: 58:351-354.

Roy A, Lin Y, Agno JE, DeMayo FJ, Matzuk MM (2007) Absence of tektin 4 causes asthenozoospermia and subfertility in male mice. The FASEB Journal 21:1013-1025.

Roy A, Lin Y, Agno JE, De Mayo FJ, Matzuk MM (2009) Tektin 3 is required for progressive sperm motility in mice. Molecular Reproduction and Development 76:453-459.

Roy SC, Atreja SK (2008) Effect of reactive oxygen species on capacitation and associated protein tyrosine phosphorylation in buffalo (Bubalus bubalis) spermatozoa. Animal Reproduction Science 107:68-84.

Roy SC, Atreja SK. (2009) Capacitation-associated protein tyrosine phosphorylation starts early in buffalo (Bubalus bubalis) spermatozoa as compared to cattle. Animal Reproduction Science 110: 319-325.

Salinovich O, Montelaro RC (1986) Reversible staining and peptide mapping of proteins transferred to nitrocellulose after separation by sodium dodecyl sulphate-polyacrylamide gel electrophoresis. Analytical Biochemistry 156:341-47. 
Sapiro R, Kostetskii I, Olds-Clarke P, Gerton GL. Radice GL, Strauss III JF (2002) Male infertility, impaired sperm motility, and hydrocephalus in mice deficient in Sperm-associated antigen 6. Molecular and Cellular Biology 22: 6298-6305.

Steffen W, Linck R (1989) Relationship between tektins and intermediate filament proteins: An immunological study. Cell Motility and the Cytoskeleton 14:359-371.

Tanaka H, Iguchi N, Toyama Y, Kitamura K, Takahashi T, Kaseda K, Maekawa M, Nishimune Y (2004) Mice deficient in the axonemal protein tektin-t exhibit male infertility and immotile-cilium syndrome due to impaired inner arm dynein function. Molecular and Cellular Biology 24:7958-7964.

Tash JS, Bracho GE (1998) Identification of Phosphoproteins Coupled to Initiation of Motility in Live Epididymal Mouse Sperm. Biochemical and Biophysical Research Communications 251:557-563.

Teves ME, Sears PR, Li W, Zhang Z, Tang W, Van Reesema L, Zhang Z, Costanzo RM, Davis CW, Knowles MR, Strauss III JF, Zhang Z (2014) Sperm-associated antigen 6 (spag6) deficiency and defects in ciliogenesis and cilia function: polarity, density, and beat. PLoS ONE 9: e107271.

Thacker JS, Yeung DH, Staines WR, Mielke JG (2016) Total protein or high-abundance protein: Which offers the best loading control for Western blotting? Analytical Biochemistry 496: 76-78.

Toshimori K, Eddy EM (2015) The spermatozoon. In Plant TM \& Zelenznik (Ed). Knobil and Neill's Physiology of Reproduction, Elsevier, New York, USA, Pp. 99-148.
Turner RM (2006) Moving to the beat: a review of mammalian sperm motility regulation. Reproduction, Fertility and Development 18: 25-38.

Vijayaraghavan S, Trautman KD, Goueli SA, Carr DW (1997) A tyrosine-phosphorylated 55-kilodalton motility-associated bovine sperm protein is regulated by cyclic adenosine 3 ',5'-monophosphates and calcium. Biology of Reproduction 56:1450-1457.

Vijayaraghavan S, Mohan J, Gray H, Khatra B, Carr DW (2000) A role for phosphorylation of glycogen synthase kinase-3 $\alpha$ in bovine sperm motility regulation. Biology of Reproduction 62: 1647-1654.

Visconti PE, Bailey JL, Moore GD, Pan D, Olds-Clarke P, Kopf GS (1995) Capacitation of mouse spermatozoa. I. Correlation between the capacitation state and protein tyrosine phosphorylation. Development 121: 1129-1137.

Wu H, Chen Y, Miao S, Zhang C, Zong S, Koide SS, Wang L (2010) Sperm associated antigen 8 (SPAG8), a novel regulator of activator of CREM in testis during spermatogenesis. FEBS Letters 584:2807-2815

Xiong, Z, Zhang H, Huang B, Liu Q, Wang Y, Shi D, Li X (2018) Expression pattern of prohibitin, capping actin protein of muscle Z-line beta subunit and tektin-2 gene in Murrah buffalo sperm and its relationship with sperm motility. Asian-Australasian Journal of Animal Science 31: 1729-1737.

Yenugu S, Hamil KG, Grossman G, Petrusz P, French FS, Hall SH (2006) Identification, cloning and functional characterization of novel sperm associated antigen 11 (SPAG11) isoforms in the rat. Reproductive Biology and Endocrinology 4: 23. doi: 10.1186/1477-7827-4-23. 